\title{
Communication of reproductive health information to the rural girl child in Filabusi, Zimbabwe.
}

\author{
Similo Ngwenya
}

National University of Science and Technology, Library and Information Science.

\begin{abstract}
Background: Despite a number of programs aimed at the transfer of reproductive health information, adolescents in Zimbabwe still face unprecedented reproductive challenges.

Objectives: The study sought to explore adolescent girls' knowledge of their sexual and reproductive health; the factors that influence their sexual behaviors and to determine the extent to which adolescents had access to sexual and reproductive health information.

Methods: The case study methodology was used for the study. The interpretive paradigm was used as the methodological theory and Grunig's model of excellence in communication was used as the substantive theory. Data was obtained through the use of focus group discussions and indepth interviews.

Results: Although adolescents knew the different types of sexually transmitted diseases and were aware of the consequences of engaging in risky sexual behaviors, they engaged in health behaviors which had potential for serious consequences. The study established that adolescents did not have adequate access to sexual and reproductive health information. Sexual issues were not adequately addressed both at school and at home.

Conclusion: Adolescents lack adequate access to reproductive health information and there is need for effective communication programs that contribute towards the understanding of communicated messages by audiences and the understanding of audiences by communicators.
\end{abstract}

Keywords: Sexual and reproductive health, adolescents, communication.

DOI: http://dx.doi.org/10.4314/ahs.v16i2.13

Cite as: Ngwenya S. Communication of reproductive health information to the rural girl child in Filabusi, Zimbabwe. Afri Health Sci 2016;16(2): 451-461. http://dx.doi.org/10.4314/abs.v16i2.13

\section{Introduction}

Adolescent sexual and reproductive health is a major public health concern ${ }^{1}$. Literature shows that the need for improved reproductive health services aimed at adolescents is widely recognized throughout the world. A number of authors and organizations ${ }^{2-7}$ report that many adolescents world over are sexually active, and in some regions, as many as half are married. Sexual activities and early marriages are detrimental to the health and wellbe-

\footnotetext{
Corresponding author:

Ngwenya Similo,

National University of Science and Technology,

Library and Information Science.

Box AC 939 Ascot Bulawayo Bulawayo

Zimbabwe

Email: simingwe@webmail.co.za
}

ing of adolescent girls and they put them at high risks of various reproductive health challenges such as unwanted pregnancies, unsafe abortions and high levels of STI and HIV infections. Global estimates indicate that every year, about 3 million adolescents (one in every eight sexually active) are infected with a sexually transmitted disease ${ }^{1}$. WHO estimates indicate that STI rates are high in subSaharan Africa with 69 million new cases per year in a population of 269 million people aged $15-49^{5}$.

Furthermore, one scholar, ${ }^{8}$ reported that in many developing countries, more than half of all new HIV infections are among young people, $15-24$ years. These statistics are worrying, considering that; currently there are more than one billion adolescents $10-19$ years, $70 \%$ of whom live in low income countries ${ }^{6}$, and also considering that; for the past years, adolescents sexual and reproductive health concerns have always been recognized globally. 
For the past decades, a number of conferences and summits have been held in Africa to come up with strategies to curtail adolescents' sexual and reproductive health challenges. In 1994, thirty eight countries from sub-Saharan Africa, Zimbabwe included committed themselves to a programme of action aimed at providing adolescents with sexual reproduction health education, information and services. This commitment came during the International Conference on Population and Development (ICPD) which called for the provision of sexual and reproductive health information and services to adolescents. The ICPD was the first UN conference to recognize the importance of sexual and reproductive health. It provided a comprehensive framework for improving people's lives. It emphasized the need for a multimedia communication approach in reproductive health communication. It charged governmental and Non-governmental organisations with the responsibility of meeting the special sexual and reproductive needs of adolescents by establishing integrated and comprehensive approaches to respond to those needs?

In the years since the ICPD, at the global level, various meetings and pronouncements reaffirmed the central role of reproductive health and reproductive rights in achieving a world free of violence against women and girls and preventing HIV/AIDS. Such events included ICPS+5, ICPD+10, United Nations General Assembly Special Session on HIV and AIDS and the Political Declaration ${ }^{8}$. Following these summits and meetings, the government of Zimbabwe embarked on a number of strategies aimed at the transfer of reproductive knowledge to the population at large. The government cabinet approved the $\mathrm{Na}$ tional Population policy. In September 2000, the National Youth policy was approved. In 2002 a Draft Reproductive health policy was made.

Recently, the National Adolescent Sexual and Reproductive Health Strategy, 2010-2015 and the National Policy on HIV/AIDS were approved. The national life skills education syllabus, mandated to be taught in primary and secondary schools, is currently under revision. The Life Skills, Sexuality, HIV and AIDS Education Strategic Plan for 2012-2015 calls for revising the syllabus to add topics such as abstinence, testing and counseling, condom knowledge and self-efficacy, age disparities between partners and male circumcision, to the school syllabus ${ }^{10}$.
Also, a wide range of stakeholders, private sectors, research institutions, NGOs and international development partners in the country engaged in the dissemination of reproductive health information through a number of health communication programs.

However, despite all these initiatives and the governments' commitment to the ICPD programme of action, young people in Zimbabwe still face unprecedented reproductive health challenges which include; high levels of teenage pregnancies and unsafe abortions. They continue being exposed to HIV and sexually transmitted diseases and they still have limited access to sexual and reproductive health information ${ }^{4}$. According to one scholar ${ }^{11}$, indicators reveal that young people in Zimbabwe show high risk behaviors. As of 2012, HIV prevalence among Zimbabwean 15-24 year olds, was at estimated 6.3\% among women and $3.9 \%$ among men, $4.2 \%$ of females and $3.4 \%$ of males were HIV-positive as of $2011^{12}$. The rural girl child suffers the most as she lacks adequate access to reproductive health information, coupled with that, a number of socioeconomic factors impede her decisions on sexual and reproductive health issues, as such, she is more vulnerable to several reproductive problems such as early marriages and unwanted pregnancies; as compared to her urban counterparts. One scholar ${ }^{7}$, revealed that $65 \%$ of rural girls are usually married or impregnated by the age of 19. Many of these pregnancies are unwanted. Mashonaland Central in Zimbabwe tops the list with 50 percent of its population getting pregnant at an early age while Mashonaland West is pegged second with 42 percent. Furthermore, another scholar ${ }^{13}$ revealed that, the birthrate among Zimbabwean adolescents' stands at 115 births per 1,000 women aged 15-19.

It is against this background that the study sought to explore adolescent girls' knowledge of their sexual and reproductive health; the factors that influence their sexual behaviors and to determine the extent to which they have access to sexual and reproductive health information. The study drew its theoretical framework from Grunig's model of excellence in communication. The model is based on the idea of strategic planning and communication management for the success of communications programs to reach intended audiences ${ }^{14}$. The emphasis on Grunig's theory is the ideal two-way symmetrical 
communication through dialogue to develop mutual understanding between organizations and their audiences. This element of the model brings about understanding and relationship building between programs and their audiences. The model is more applicable in reproductive health communication programs and other development organisations where understanding is needed for any change. It is essential for programs to understand audiences and identify what they know and why they behave in the manner they do so as to come up with effective and behavioral changing communication strategies ${ }^{15}$.

\section{Definition of terms}

\section{Adolescent girls}

This term is used in the study to refer to young girls between 13-19 years. One scholar, ${ }^{16}$ defined adolescence as a period of transition from childhood to adulthood. Adolescence involves a rapid change in many aspects including the biological, psychological and socio cultural ${ }^{16}$.

\section{Sexual and reproductive health}

The 1994 ICPD Programme of Action defined reproductive and sexual health in the context of primary health care to include:

a) Family planning

b) Antenatal, safe delivery and post natal care

c) Prevention and appropriate treatment of infertility

d) Prevention of abortion and management of the consequences of abortion

e) Treatment of reproductive tract infections

f) Prevention, care and treatment of STIs and HIV/AIDS

g) Information, education and counseling as appropriate on human sexuality and reproductive health

h) Prevention and surveillance of violence against women, care for survivors of violence and other actions to eliminate traditional harmful practices such as female genital circumcision/mutilation

i) Appropriate referrals for further diagnosis and management of the above ${ }^{8}$

While ICPD defined sexual and reproductive health in a broad way, sexual and reproductive health shall be used in the study in the context of primary health care to include; information, education and counseling as appropriate on human sexuality and reproductive health, prevention, care and treatment of STIs and HIV/AIDS and prevention of unwanted pregnancies and abortion.

\section{Sexual and reproductive health rights}

Sexual and reproductive health rights include the right of all persons to:

-Seek, receive and impart information related to sexuality;

- Receive sexual education;

- Have respect for bodily integrity;

- Choose their partner

-Decide to be sexually active or not;

-Have consensual sexual relations'

- Have consensual marriages

- Decide whether or not to and when to have children

-Pursue a satisfying, safe and pleasurable sexual life ${ }^{17}$

\section{Risky sexual behaviors}

The term risky sexual behaviors is used to refer to sexual behaviors which increase adolescent girls' chances of contracting or transmitting diseases, and the occurrence of unwanted pregnancies.

\section{Methodology}

The study was carried out from the $16^{\text {th }}$ to the $20^{\text {th }}$ of February 2015 in Filabusi, a mine town found in Matabeleland South province of Zimbabwe which is predominantly rural. The district has a total population of 52,776 of which, $53 \%$ of them are female ${ }^{18}$. Because of the high levels of unemployment, both men and women engage in illegal gold mining. It is at the mine sites that most young girls engage in risky behaviors which result in consequences such as unwanted pregnancies, sexually transmitted infections and $\mathrm{HIV}^{19}$.

The case study methodology was used for the study. The main advantage of the case study is its ability to probe deeply, analyse intensively and get an in depth and detailed understanding of the phenomenon under review. The theoretical framework guiding the study was qualitative in nature, hence, the study landed itself to the interpretivism approach. The interpretive paradigm is characterized by a concern for the individual ${ }^{20}$. It seeks to understand the subjective world of human experience. The interpretive paradigm was adopted in this study so as to understand adolescent's knowledge of their sexual and reproductive health. The combined inductive and deductive approach was used. Although there is general argument that qualitative studies employ the inductive approach and theories are the outcome of the research process, several studies 
have shown that a qualitative inquiry may also test theory or explanations for a phenomenon ${ }^{21}$. Hence, the interpretive paradigm was used in the study as the methodological theory and Grunig's model of excellence in communication was used as the substantive theory.

Data was gathered from 39 in and out of school girls through the use of focus group discussions. The girls were aged between 13 and 19 years. Six focus group discussions were held from three Wards in Filabusi, Insiza South District, and ward 1, 2 and 3. Two focus groups were held in each ward, one with in-school and the other with out-ofschool adolescent girls. Each focus group had 6 to 7 participants. Focus groups may be one of the few research tools available for obtaining data from children ${ }^{22}$. Focus groups are suitable for children because they can capture their perspectives, original ideas, and insights, which are often neglected in more traditional pediatrics research. They also serve as an innovative approach to understanding children's experiences from a developmental perspective $^{23}$. Focus group discussions were conducted so as to gather information on adolescents' knowledge, attitudes and concerns about their sexual health.

In depth interviews were further conducted with 6 girls who were in the focus groups. These interviews were held to follow up on discussions made in the focus group discussions. Three school teachers, two representatives from Insiza Godhlwayo AIDS Council, one librarian and the one health community worker were also interviewed. The goal of conducting one-on-one interviews with all these seven respondents was to gather information on the communication channels used to transfer reproductive health information to the rural adolescent girl child, and to try and understand the challenges faced when transferring reproductive health information to the adolescent girl. Two parents were also interviewed to understand the patterns of communication transfer between daughters and their parents. Convenience sampling was used to select participants from the 3 wards. Representatives from the various organizations in the study were purposively sampled based on the assumption that they engaged in the communication of information to the community.

Data was analyzed through content analysis. Brief notes were made when relevant information was found. Information was categorized into themes in a way that offered description on adolescents' knowledge of sexual and reproductive health. Recurring themes were examined separately in detail so as to ascertain if the underlying sub-themes were also the same. Where it was applicable, that is, if the underlying sub-themes were the same, for instance, why girls indulged in sexual activities, the themes were merged. Furthermore, Analysis for the study involved examining transcriptions of the recorded interviews and notes acquired during data gathering. An audio recording device was used with the respondents' permission and the information gathered formed the basis for discussion in the one-on-one in depth interviews. When using the case study design, one has to visit the respondent at the natural settings and document real events, record what they say, observe their behavior as they are immersed in their natural setting of everyday life ${ }^{24}$.

Permission to carry out the study was obtained from the Filabusi rural district administrator. Permission was also sought from parents and guardians of the respondent girls and from school authorities. The researcher informed the participants about the purpose of the study, expected duration and procedure. The participants were also informed about the uses of their contributions and they were assured of their confidentiality. Parents and guardians consented to their children being interviewed even in their absence.

\section{Results}

Responses from focus group discussions and interviews with the adolescent girls

\section{Knowledge on sexual and reproductive health}

The study aimed at exploring adolescent girls' understanding of sexual and reproductive health.

The girls were asked to identify types of sexual transmitted diseases (STDs), to explain ways of preventing and treating (STDs), to explain what is meant by risky sexual behaviors and the consequences of engaging in risky sexual behaviors.

\section{-In-school adolescent girls (aged between 13 and 18)}

Sexually transmitted diseases identified by the in school girls were HIV, syphilis, gonorrhea and herpes. Syphilis was cited as the most common sexually transmitted infection amongst youths. Respondents said STDs could be treated in clinics. Seventeen out of twenty in school girls said STDs could be prevented by either abstaining from sexual activities or using protection when engaging 
in sexual activities. In explaining what they understood by risky sexual behaviors, some respondents said the term meant "having many sexual partners" while some said "having unprotected sex". The consequences of engaging in risky sexual behaviors were "unwanted pregnancies and the contraction of sexually transmitted diseases such as AIDS".

\section{-Out of school adolescent girls (aged between 14 and 19)}

Sexually transmitted diseases identified by out of school girls were Syphilis, Gonorrhea and Herpes and AIDS. All the girls agreed in consensus that these diseases were caused by having many sexual partners and engaging in unprotected sex. Treatment of STDs was said to be found in clinics. Risky sexual behaviors where explained as "having many sexual partners" and some said risky sexual behaviors meant "sleeping around". People who "slept around" were said to end up contracting diseases and getting pregnant.

\section{Factors influencing risky sexual behaviors}

The study sought to understand why adolescent girls behaved in the manner they did, that is, why they engaged in risky sexual behaviors. Respondents were asked to report on either their own experiences or on experiences of their peers.

\section{-In-school adolescent girls}

In school girls were asked the age in which their peers started engaging in sexual activities, and sixteen girls out of twenty girls in the three groups revealed that they knew a number of their peers who started engaging in sex at secondary school. At this stage, most of them would be between 14 and 15 years. Respondents revealed that their peers were in sexual relationships with young boys of their age and some with older men who were working. The major reasons raised in the discussions for engaging in sexual activities were; peer pressure and for monetary gains. One respondent said "girls engage in sexual activities with older men so that they can have money to buy nice clothes and delicacies such as biscuits and chocolates from our local shops". One other respondent said "girls drop out of school and get married"

Respondents were asked whether their peers or they used protection when having sexual intercourse. All respondents agreed in consensus that in most cases, condoms were not used. One major reason for not using protec- tion was trust. One respondent said "when people know and trust each other, they do not use protection" Respondents were asked whether they perceived themselves as at risk of contracting sexually transmitted infections and HIV/AIDS, and most of them said they were not at risk as they have never felt sick or fell sick even when they were engaging in sexual activities

\section{-Out of school youths}

It emerged in the study that most of the out of school girls were in sexual relationships. Fourteen out of nineteen girls already had a child. Respondents said their pregnancies were not planned. Participants revealed that they left school after finishing primary education because their parents and guardians did not have money to pay for their school fees. Seventeen out of nineteen girls revealed that they started being in sexual relationships because they were not going to school. Respondents were asked whether they had consensual sexual relations with their partners. In response, the girls said they consented to sex with their partners. The girls further revealed that in most cases, they hardly used protection, and some of the reasons for not using protection were;

"It was my first time so we did not use"

"My partner did not use and I did not ask"

"I was afraid to ask"

"We trusted each other and did not see any need"

"I knew my partner so there was no need"

Asked how they protected themselves from getting pregnant, 12 out of 19 respondents said they were taking contraceptives. Respondents were asked whether they perceived themselves as at risk of contracting sexually transmitted infections and HIV/AIDS, and most of them said they were not at risk.

\section{Awareness on rights to sexual and reproductive health information}

The study sought to determine the extent in which adolescent girls had access to sexual and reproductive health information. Respondents were asked to indicate whether they had knowledge of organizations that offered reproductive health education, to describe the kind of services offered by the organizations. They were also asked whether they sought sexual and reproductive health information from the mentioned organizations

\section{-In-school girls}

The in-school girls identified the local clinic, Insiza 
Godhlwayo Aids council (IGAC), World vision and schools as the main sources of reproductive health information. Three out of twenty respondents cited the radio and television as other sources of reproductive health information.

However, of all the 20 in-school girls, 8 said they had radios at home at, 2 said they had televisions. The girls said they had guidance and counseling sessions at school; and, during these sessions, they were taught about sexual and reproductive health. Respondents also said organizations such as IGAC came to their schools to educate them. The respondents said the clinic provided counseling and advice services about the dangers of early sexual activities, unplanned pregnancies, abortions, STIs and contraceptives. Asked whether they discussed sexual issues at home with their parents, 15 out of 20 girls said they did not discuss with their parents, rather they would prepare to discuss such matters with their friends or siblings.

\section{-Out of school girls}

The out of school girls identified local clinics and community health workers as their main sources of sexual and reproductive health information. They said they received contraceptives from the clinic. They however said they did not go to the clinics to seek for information on sexual and reproductive health but either to take their children for immunization or to seek contraceptives. Respondents were asked whether they discussed about sex at home with their parents or relatives, and all of them said they never talked about sex with their parents or siblings. Instead, they confided in their friends.

Interview responses from 3 school teachers, 2 representatives from Insiza Godhlwayo AIDS Council, one librarian and the 1 health community worker and 3 parents

The study also sought to investigate the communication strategies used to transfer reproductive health information to the rural girl child. Respondents were asked how they communicated sexual and reproductive health information to the adolescent girls and to explain challenges faced when disseminating that information

\section{-Insiza Godhlwayo Aids Council}

Respondents from Insiza Godhlwayo Aids Council (IGAC) revealed that adolescents' sexual reproductive health was conducted through sport. The organisation supplies youths with sporting materials. Sexual reproduc- tive health rights information was shared with the youths during activity breaks and after the games. One respondent also said "IGAC also works closely with the Ministry of primary and Secondary Education (MOPSE) district office to train teachers to empower boys and girls. It also works with the Ministry of Health and Child Care and Positive Action for Children Fun (PACF) to create demand for the PMTCT services."

One major challenge faced by IGAC when communicating sexual and reproductive health information was said to be government policy. They said government policy did not allow them to teach adolescents about condom use in schools. Respondents revealed that government policy requires them to train teachers on reproductive health information; teachers would then pass on the information to pupils. They said they had to get to the school pupils via the teachers and this was not an effective method of transferring information. The communication channel was disturbed and messages got to the intended audiences distorted

\section{-School teachers}

The school teachers in the study said they had guidance and counseling sessions with in-school girls. During these sessions, school children were taught on a number of sexual and reproductive health issues such as prevention and treatment of sexually transmitted infections, menstruation, rape and basic life skills. These sessions were scheduled for once a week. However, the teachers said communicating sexual and reproductive health information through guidance and counseling was not pronounced. One school teacher said one factor that hindered them from conducting guidance and counseling was that they had a packed curriculum which made it almost impossible to have guidance and counseling sessions. She said scheduling of guidance and counseling was not fixed, hence they could go for weeks without having the sessions.

\section{- Community health worker}

The community health worker said they distribute pamphlets which have information on sexual and reproductive health information. The community health worker revealed that people from the community still had negative perceptions about HIV/AIDS. She pointed out that some community members discriminated people who were infected and they did not want to be seen with village health workers fearing that they would be associated with HIV. 


\section{-Parents}

Two parents in the study revealed that they did not talk about sex with their children. They said they talked about menstruation. One elderly woman said "times have changed; we do not sit and talk with these children anymore. They do not listen to us and they say we are backward". The woman also said "the girls of this new generation are wild and disrespectful and they don't listen to elders, that is the reason they are getting pregnant and getting diseases".

Two other parents said they believed that students were taught about sexual and reproductive health at school. One mother said organizations such as IGAC educated girls on the dangers of unprotected sex, unwanted pregnancies and HIV/AIDS.

\section{-Librarian}

The librarian interviewed in the study pointed out that the library was close to closure as it did not have any resources and it lacked funding.

\section{Discussion}

\section{Knowledge on sexual and reproductive health}

The study established that both in-school and out of school girls were aware of a number of sexually transmitted diseases and they were aware of the dangers of engaging in risky sexual behaviors. However, what emerged in the study was that the girls were engaging in risky sexual behaviors. This proves to show that knowledge of reproductive health does not necessarily mean a change of sexual behavior. This implies that there is usually lack of understanding of sexual and reproductive issues. Lack of understanding of communicated messages makes it difficult for behavioral change to occur among targeted audiences regardless of their awareness ${ }^{13}$. To reinforce this assertion, scholar ${ }^{10}$ stated that most Zimbabwean adolescents know the two most common ways to prevent HIV infection, abstinence and use of condoms; but they lack more in-depth understanding, as shown by their only moderate levels of comprehensive knowledge.

For effective communication, providers need to know about the various health issues of their target groups and understand why they behave in the manner they $\mathrm{do}^{13}$; as stated in Grunig's model of communication that for effective communication, there has to be some understand- ing between audiences and communicators. The model stresses on understanding the audience and building a relationship with them as important components for behavioral change. Scholar ${ }^{10}$ said some of the stigma toward adolescents being sexually active outside of marriage could be addressed through community education campaigns, which need to be conceived and conducted in local languages to resonate in local contexts. Poverty and peer pressure were cited as the main reasons for engaging in risky sexual behaviors. From the study, fourteen out of nineteen out of school girls already had a child. These girls revealed that they dropped out of school because of lack of money to pay school fees. Several studies reveal that once girls drop out of school, they are married off by their parents. According to scholar ${ }^{7}$, in Zimbabwe, it is normal for a fourteen year old girl to be married off and drop out of school.

Many parents in the country use marriage as a mitigating factor for failure to pay school fees due to economic challenges ${ }^{7}$. To add on, poverty, traditional beliefs and teenage sex are major reasons for early child marriages in Zimbabwe. Early marriages are detrimental to health and the wellbeing of the girl child ${ }^{25}$.

"Child marriages can also result in bonded labour or enslavement, commercial sexual exploitation and violence against the victims. Because they cannot abstain from sex or insist on condom use, child brides are often exposed to such serious health risks as premature pregnancy, sexually transmitted infections, and, increasingly, HIV/AIDS, ${ }^{\prime 7,25}$.

In explaining the causes of adolescent's early sexual debuts, scholar ${ }^{26}$ stated that the reasons why young people engage in sexual behaviors are complex and diverse and have been attributed to various social context and familial factors. The determinants of sexual behavior are a function, not only of the individual but of structural and environmental factors as well ${ }^{26}$. Hence focus should be on the wider social economic context that surround people rather than on exclusively behavioral influences on individuals. The study establishes that there is need for appropriate communication channels which take into account the technical formats of messages; information needs behavior, norms, values, beliefs and socio-cultural context of rural communities. These factors dictate how 
adolescents perceive their risks of contracting sexually transmitted infections and how they deal with them when affected. The factors also influence adolescent girls' decisions to take protective measures or not when engaging in sexual activities. Grunig's excellence in communication model stresses that understanding audiences; that is inclusive of economic and socio-cultural factors surrounding them, and building relationships with them is an important component for behavioral change.

\section{Access to sexual and reproductive health informa- tion}

The study found that the adolescent girls did not have adequate access to sexual and reproductive health information. The community library in Filabusi, strategically set to provide information on health and sexual matters faced challenges of funding and was close to closure. This is the case with most community and school libraries in Zimbabwe. Literature shows that libraries in Zimbabwe face a myriad of challenges which include lack of resources, lack of skilled personnel and poor funding.

Respondents in the study revealed that they did not seek sexual and reproductive health information. Instead they discussed such issues with their friends. These findings were also noted in a separate study by Obono ${ }^{27}$ who stated that young people are less likely willing to seek professional help for more sensitive matters and turn readily to friends and family whom they feel they can trust for sexual advice. The study further found that sexual matters were not talked about at home.

Extended parents, aunts, uncles and grandparents are traditionally the main communicators of sexual and reproductive health values and conduct to young people ${ }^{27}$, but, "the introduction of formal education systems shifted the roles of educating and informing adolescents from the community to teachers"12. This transition has not helped the adolescents because teachers usually have a packed curriculum and hardly find time to take pupils for sexual and reproductive lessons, as noted in the findings on the study. To add on, scholar ${ }^{1}$ noted that the lack of curricula and lack of training skills on sexuality matters also makes teachers shy away from teaching sexuality education. A number of studies found that lack of child to parent communication on sexual matters puts adolescents at higher risks of being susceptible to sexual and reproductive challenges.
Parent to child communication on sexual and reproductive health matters is a tool that proves to be beneficial in the prevention of HIV and AIDS among young people ${ }^{28}$. Evidence shows that young people who receive clear information on sexual conduct from parents are more able to practice risk reduction behaviors such as delay of sexual debut and consistent condom use $\mathrm{e}^{28}$.

Hence, scholar ${ }^{10}$ advised that encouraging parent-child communication, which is a "key strategy" in the Zimbabwe adolescent and sexual health strategy Addendum of 2010-2015, would help strengthen both generations' understanding of the epidemic and how to protect against HIV and unintended pregnancy.

Furthermore, the study found out that adolescent girls have wrong myths and beliefs pertaining to sex. Some respondents revealed that they would not get pregnant on their first encounter of sex. Several other studies on reproductive health revealed that adolescents have wrong myths and perceptions when it comes to sex. For instance, scholar" reported that "adolescents believe that conception can be prevented when one takes a bath immediately after a sexual encounter, by having sex standing up or by jumping up and down after sex". Providing young people with sexual and reproductive health information and services is key to enable them to make well informed choices about their sexual and reproductive health. Young people in Zimbabwe need to be empowered with correct, updated and age appropriate life skills to adopt and maintain safe, healthy and responsible sexual attitudes and behaviors $^{29}$. This includes equipping them with skills that encourage abstinence, delayed first sex, faithfulness in relationships and contraceptive use among unmarried young people.

\section{Challenges faced when disseminating sexual and re- productive health information}

Adolescents are embedded within policy, cultural, economic and social contexts that influence their access to sexual and reproductive health information. Sexuality matters are seen as taboo for adolescents. Sex is seen as sacred and often a topic for the married ${ }^{1}$. Furthermore, parents and providers fear that providing unmarried adolescents with information on contraception to prevent pregnancy in general, and on condoms to prevent HIV in particular, will lead to their becoming sexually active at a young age ${ }^{12}$. However, the truth of the matter is that youths are already engaging in risky sexual activities. In- 
dicators reveal that young people in Zimbabwe show high risk behaviors. Statistics reveal that, as of 2012, HIV prevalence among Zimbabwean 15-24 year olds was at an estimated $6.3 \%$ among women and $3.9 \%$ among men, and, among 15-19-year olds, $4.2 \%$ of females and 3.4\% of males were HIV-positive as of $2011^{11}$. Young people are engaging in sexual intercourse at an early age, and have unplanned pregnancies. In a report by scholar ${ }^{30}$, it was revealed that $34 \%$ of adolescent females have had sexual intercourse, as have $25 \%$ of adolescent males. To add on, scholar ${ }^{10}$ pointed out that females marry at an early age.

Hence; "Contrary to common belief, providing comprehensive sex education to young people does NOT encourage them to be sexually active. In other words, giving children and young people the opportunity to receive correct information, learn how to live by their values, and acquire relationship skills will enable them to make the rights choices and become responsible and respectful adults," 31

One other major barrier to communication of reproductive health information is that the government of Zimbabwe and the majority of elders in the country emphasize on the doctrine of abstinence when in actual fact, youths are already engaging in risky sexual activities. Even though a number of organizations propose the use of condoms, scholar ${ }^{32}$ lamented that increasing condom use is challenging in a country where the majority of adults $63 \%$ of women and $52 \%$ of men do not believe that 12-14-year-olds should be taught about how condoms can prevent HIV infection. Opposition to such instruction is far stronger in rural than in urban areas $(16 \%$ higher among women and $23 \%$ higher among men) ${ }^{32}$. Adults' (including many likely parents) widespread disapproval of teaching about condom use in school makes it difficult for adolescents to learn how to protect themselves from HIV infection. In one incident, the Ministry of Primary and Secondary education in Zimbabwe Dr Dokora, was quoted saying, parents who were concerned about provision of condoms for their children should instead include them when they pack their children's school backpacks ${ }^{33}$. Dr Dokora went on to say "Education must promote Ubuntu, no condoms in schools" this implies that teaching youths on condom use was not socially acceptable.

African Health Sciences Vol 16 Issue 2, June 2016

\section{Conclusion}

The study found that, although adolescents were aware of the dangers of engaging in unprotected sexual activities, they still engaged in health behaviors which had potential for serious consequences. The study established that adolescents did not have adequate access to sexual and reproductive health information. Sexual issues were not adequately buttressed both at home and at school. The study posts that there is need for the encouragement of parent-child communication, young people who receive clear information sexual conduct from parents are said to be more able to practice risk reduction behaviors such as delay of sexual debut and consistent condom use. Furthermore, there is a need for appropriate communication channels which take into account the technical formats of messages; information needs behavior, norms, values, beliefs and socio-cultural context of rural communities. These factors play pivotal roles in influencing adolescents' decisions regarding their sexual health as stipulated by the excellence in communication model that understanding audiences and building relationship with them are important components for behavioral change.

\section{Recommendations}

-Focus on sexual and reproductive health issues should be on the wider social economic context that surround people rather than on exclusively behavioral influences on individuals.

- Policy makers and stakeholders involved in the provision of reproductive health information and services to adolescents should come up with effective communication strategies that lead to behavioral change.

-Young people in Zimbabwe need to be empowered with correct, updated and age appropriate life skills to adopt and maintain safe, healthy and responsible sexual attitudes and behaviors. This includes equipping young people with skills that encourage abstinence, delayed first sexual encounter, faithfulness in relationships and contraceptive use among unmarried young people.

-Library and Science professionals have to take a proactive role in helping marginalized information users with specialized information needs such as rural adolescent girls.

\section{References}

1. Kamau, AW. Factors Influencing access and utilization 
of preventive reproductive health services by adolescents in Kenya. A case study of Muran'a District, 2006. [Online]. Available at: www.pub.uni-bielefeld.de/publication/2305119.html accessed 27/01/2015. [Accessed: 27 January, 2015].

2. Blanc, A. and Way, A. Sexual behavior, contraceptive knowledge and use. Studies in family planning 29(2) 106-116 cited in Outlook 1998 Adolescent Reproductive Health: Making a difference Volume 16 number 3, 1998. 3. United Nations Population Fund. Partnering: A new approach to Sexual and Reproductive Health. New York UNFPA 2000

4. United Nations Population Fund. 2011. Adolescent sexual and reproductive health: UNFPA. [Online]. Available at: www.unfpa.org/.../adolescent-sexual-and-reproductive-health-toolkit-hu [Accessed: 27 January, 2015].

5. World Health Organization. Prevention and Control of Sexually Transmitted infections: Draft Global Strategy. WHO 2006

6. Atuyambe, L. Adolescent motherhood in Uganda: Dilemmas, Health seeking behaviors and coping Responses. 2008 [online] Available at www.makir.mak.ac.ug/handle/105701798 [Accessed: 27 January 2015]

7. Mangirazi, N. Rural girls dropping out of School for marriage. The Financial Gazette- Zimbabwe News 2015 [Online] Available at www.financialgazette.co.zw [accessed 2 October 2015]

8. United Nations Population Fund, 2008. Reproductive rights and sexual and Reproductive health Framework: UNFPA. [Online] available https://www.unfpa.org/ sites/default/files/pubpdf/SRH_Framework.pdf [Accessed 02 September 2015]

9. Ngozi, A. S. Towards breaking the conspiracy of silence in reproductive health information access among in school adolescent girls in Lagos Nigeria. Conference paper presented at the 2014 AHILA conference. 2014 [Online] Available at www.tudarco.ac.tz/.../AHILA\%20 14\%20Program_final $\% 20$ version $\% 20$ u... [Accessed 20 March 2015]

10. Ministry Ministry of Education, Sport, Arts and Culture, Life Skills, Sexuality, HIV and AIDS Education Strategic Plan, 2012-2015, Harare, Zimbabwe: Ministry of Education, Sport, Arts and Culture, 2012

11. Remez L, Woog V and Mhloyi, M, Sexual and reproductive health needs of adolescents in Zimbabwe, In Brief, New York: Guttmacher Institute, 2014, No. 3.
12. Zimbabwe National Statistics Agency (ZIMSTAT) and ICF International, Zimbabwe Demographic and Health Survey, 2010-2011, Calverton, MD, USA: ZIMSTAT and ICF International, 2012.

13. Mashamba A and Robson E. 2002. Youth reproductive health services in Bulawayo, Zimbabwe, Health \& Place, 2002, 8(4):273-283.

14. Gruning, J.E. Two-way symmetrical public relations: past present and future in $\mathrm{R} /$ Health. Handbook of public relations. 1995 Thousand Oaks, Sage

15. Muturi, N. W. Cultural Considerations in HIV/AIDS communication and prevention in Kenya, 2005. Journal of bealth communication 10 (1)77-98

16. Sitomurang, A. Adolescent reproductive health in Indonesia. 2003 [Online] available www.usaid.gov/pdf_ docs/Pnacw743.pdf [ Accessed 02 March 2014]

17. World Health Organization. Health for the World's adolescents: A second chance in the second decade. Geneva: WHO 2014. [online] available http://apps.who.int/ adolescents/seconddecade/files/1612_MNCAH_Executive_summary.pdf [ Accessed 03 March 2014]

18. Insiza South Constituency profile 2011 [Online] available www.almin.co.zw/attachments/article/134/Insiza\%20South.pdf accessed 08 June 2014

19. Ngwenya, S, and Matingwina, T. Health information needs and seeking behavior of rural women in Filabusi District, Zimbabwe. Conference paper presented at the 2014 AHILA conference [Online] Available at www.tudarco.ac.tz/.../AHILA $\% 2014 \% 20$ Program_final $\% 20$ version\%20u.. [Accessed 20 March 2015]

20. Cohen, L. 2011. Research Methods in Education. $7^{\text {th }}$ Edition, Rout ledge Taylor and Francis Group, London and New York

21. Ngulube, P. Mathiba E, R and Gumbo M, T. Theoretical and Conceptual Frameworks in the Social and Management sciences. 2015 [Online] available https://www. academia.edu/14019101/Theoretical_and_Conceptual_ Frameworks_in_the_Social_and_Management_Sciences [Accessed 20 August 2015]

22. Marczak, M. Using focus groups for evaluation. 2013 [Online]. Available from:www.ag.arizona.edu/.../focus. html [Accessed 02 March 2014]

23. Kenny, C. 2007. Methodological considerations in children's focus groups [Online] available www.ncbl.nlm [Accessed 02 March 2014]

24. Tichapondwa, S, M. Preparing your dissertation at a dis- 
tance: A Research Guide 2013. [Online] Available at www. sadc.int/index.php/download_file/view/2245/891/ [Accessed 20 April 2015]

25. Mangirazi, N. Rural girls dropping out of School for Marriage 2015. [Online] www.topnews.co.zw/ $\mathrm{read} / 214828 /$ [Accessed 20 August 2015]

26. Wamoyi, J et al 2010 Parent - Child communication about sexual and reproductive health in Tanzania: Implications for young people's sexual health interventions 2010 [Online] available www.reproductive-health-journal. com/content/7/1/6 [Accessed 03 March 2014] 27. Obono, K. Patterns of Mother Daughter communication for Reproductive health knowledge transfer in Sothern Africa. Journal Canadian Edition Vol 5 issue 12012 [Online] available www.gmj.uottawa.ca/1201/v5i1_obono.pdf [ Accessed 27 January 2015]

28. Maleta, T. Parent and Child communication on sexual and reproductive health matters in Malawi 2016 [Online] available: www.medcolmw/mph [Accessed 11 June 2014] 29. Biriwasha, M, K. Young Zimbabweans face sexual and reproductive health rights challenges 2012. [online] available https://developmentagezim.wordpress.com/.../ young-zimbabweansfaces... [Accessed 20 April 2015] 30. CSO and Macro International, Zimbabwe Demographic and Health Survey, 2005-2006, Calverton, MD, USA: CSO and Macro International, 2007.

31. Washaya, Y. Zimbabwe launches an education strategy on life skills, sexuality and HIV and AIDS 2013 Speech by Hossain R, [Online] available www.unicef.org/zimbabwe/media_13776.html [Accessed 03 March 2014] 32. Chitereka J and Nduna B. Determinants of Unmet Need for Family Planning in Zimbabwe, Harare: Zimbabwe National Family Planning Council and Liverpool School of Tropical Medicine. 2010.

33. The Herald: No condoms at Schools 2015 [Online]http://www.sundaymail.co.zw/?p=24635 [Accessed 20/04/15] 